\title{
Determination of Factors Effecting Medication Adherence in Depressed Patients Receiving Antidepressants in Pakistan
}

\author{
Muhammad Amir ${ }^{1,2, *}$, Nathanial Rickles ${ }^{3}$, Zeeshan Feroz ${ }^{4,5}$, Anwer Ejaz Beg ${ }^{2}$ \\ ${ }^{1}$ Pharmacy Department, Lady Reading Hospital, Peshawar, Pakistan \\ ${ }^{2}$ Faculty of Pharmacy, Ziauddin University, Karachi, Pakistan \\ ${ }^{3}$ School of Pharmacy, University of Connecticut, USA \\ ${ }^{4}$ Basic Sciences Department, College of Science and Health Professions, King Saud bin Abdulaziz University for \\ Health Sciences, Riyadh, Kingdom of Saudi Arabia \\ ${ }^{5}$ King Abdullah International Medical Research Center, Riyadh, Kingdom of Saudi Arabia
}

Authors' Contributions

1 conceived the idea, designed the project and wrote the manuscript.

2,3,4 participated in the design of the study and editing of the manuscript.

All authors reviewed and approved the final manuscript.

\section{Acknowledgement}

Prof Dr Kamran Hameed for his guidance and supports.

Article info.

Received: May 19, 2020

Accepted: July 30, 2020

Funding Source: Nil

Conflict of Interest: Nil

Cite this article: Amir M, Rickles N, Feroz Z, Beg AE. Determination of Factors effecting Medication Adherence in Depressed Patients Receiving Antidepressants in Pakistan. RADS J Pharm Pharm Sci. 2020; 8(1):1-6.

*Address of Correspondence Author: mohd_amir80@hotmail.com

\section{ABSTRACT}

Background: The prevalence of depression in Pakistan is considered to be higher than other developing countries. Medication adherence is a major factor in the success and cost effectiveness of the treatment of depression. Limited information relating medication adherence and its factor are available for patients in Pakistan.

Objective: The study aim to determine the factors associated with adherence of antidepressants in depressed patients.

Methods: The study was conducted in outpatient setting of hospital. 200 participants were enrolled in the study. Self-assessment tool was used to determine the medication adherence.

Results: The results showed that factors such as gender, education, employment and total number of medications have significant influence on adherence of antidepressants. The study also shows that the relationship of factors and adherence changes with the duration of therapy.

Conclusion: Factors play a vital role in understanding the barriers in medication non-adherence. Factors effecting medication adherence change with respect to the duration of therapy. Gender, employment, morbidity and number of medications taken earlier have significant influence on medication adherence of antidepressants in depressed patients.

Keywords: Medication adherence, Factors, Antidepressants, Karachi, Pakistan, Depression.

\section{INTRODUCTION}

Medication adherence is defined as "the extent to which a patient act in accordance with the prescribed interval, dose, and dosing regimen" [1]. Poor medication adherence is termed as medication non- adherence [2]. Medication non-adherence is considered when medication adherence is less than $80 \%$ [3]. Medication adherence is a global concern which is associated with increased risk of mortality, morbidity and healthcare cost. Researches have 
shown that half of the patients do not take their medication as prescribed [4].

World Health Organization (WHO) defines depression as common mental disorder that presents with depressed mood, loss of interest or pleasure, feelings of guilt or low self-worth, disturbed sleep or appetite, low energy, and poor concentration [5]. Depression is considered fourth leading cause of disability and premature death in the world [6]. It is estimated that in developing countries about 25 individuals amongst hundred suffers from some mental disease in any part of their life [7]. Adherence is a major factor in the success and cost effectiveness of the treatment of depression [8].

The current standard of treatment for depression is antidepressants [9]. Pharmacotherapy of depression includes Monoamine Oxidase Inhibitors (MAOls), Tricyclic Antidepressants (TCAs), Selective Serotonin Reuptake Inhibitors (SSRIs), and SerotoninNorepinephrine Reuptake Inhibitors (SNRIs) [10]. Tricyclic antidepressants have been replaced by SSRI as first line of therapy due to low toxicity profile, however SSRI have a greater cost [11].

Adherence is a major factor in the success and cost effectiveness of the treatment of depression [8]. Patients with psychiatric illness are highly affected by non-adherence; hence can benefit greatly by adherence improving interventions [11]. $68 \%$ of depressed patients discontinue antidepressants within three months of therapy initiation, whereas those patients who continued to take their medications, fewer than $33 \%$ consistently take the antidepressant as prescribed [12]. Delayed response and adverse drug reactions (ADRs) are the major factors that contribute to non-adherence [13]. Another study revealed that amongst antidepressants users $25.4 \%$ had potential contraindications or major interactions, $36.1 \%$ had moderate drug interactions and $38.5 \%$ had minor or no interactions [14].

Non-adherence is common irrespective of the therapeutic class of antidepressants and stages of treatment, i.e. acute, continuation and maintenance. The crucial period with increased risk of treatment drop-out, medication discontinuation and vulnerability of suicide is the first six weeks (early phase) of the treatment [15].

Limited information is available regarding factors effecting adherence of antidepressants in Pakistan. Furthermore, many of these published literatures are based on cross sectional studies. This study was conducted to determine the effect of text message base intervention on adherence of antidepressants in depressed patients. One of the aims of this study was to determine factors effecting medication adherence and have been described in this paper.

\section{MATERIALS AND METHODS}

\section{Study Design}

A single center, single-arm design, open label study conducted in outpatient clinics. The outpatient clinic was associated with a private hospital located in high socioeconomic status community. No blinding was conducted due to the nature of intervention.

\section{Participants}

The participants of the study were the patients who visited the clinic. The inclusion criteria of this study were adult patients diagnosed with depression and were prescribed oral antidepressants (not more than two weeks). The exclusion criteria included patient below 18 years old or patients who had active suicidal ideation, psychotic depression or a history of mania or inability to communicate in Urdu or English language or sign of dementia/ impaired cognitive.

\section{Participants Selection}

Physician after identifying a suitable candidate for the study were referred to clinical pharmacist. Clinical pharmacist provided all the information related the study. Nurse and physician were informed about those patients who agreed to be the part of the study.

\section{Data collection}

The process of collection of data is fully explained in another paper [16]. Clinical pharmacist was responsible to collect the data at the baseline, at $3^{\text {rd }}$ months and 6 months. A self-assessment tool was used to assess medication adherence and classify the participants into full adherent, partial adherent and non-adherent [17]. The details of classification of medication adherence status is given in Table $\mathbf{1}$

\section{Data Analysis}

Categorical variables such education, sex, employment status and comorbidities and other demographic information were summarized with the help of frequencies and percentages. Kendall correlation analysis was utilized to evaluate relationship between factor and medication adherence. All analyses were carried out using Statistical Packages for Social Sciences version 21 
(SPSS Inc., Chicago IL, US). Statistical significance was indicated by $\mathrm{p}<0.05$.

Table 1. Classification of Medication Adherence Status.

\begin{tabular}{|c|c|c|}
\hline Classification & Level & Description \\
\hline \multirow[b]{2}{*}{ Fully adherent } & 1 & $\begin{array}{l}\text { High drug adherence: No } \\
\text { missing doses and no } \\
\text { schedule errors }\end{array}$ \\
\hline & 2 & $\begin{array}{c}\text { Good drug adherence: } \\
\text { No drug holidays and no } \\
\text { missing doses; schedule } \\
\text { errors } \geq 4 \mathrm{~h}\end{array}$ \\
\hline $\begin{array}{c}\text { Partial } \\
\text { adherent }\end{array}$ & 3 & $\begin{array}{c}\text { Moderate drug } \\
\text { adherence: No drug } \\
\text { holidays; missing doses } \\
\text { once or twice a month } \\
\text { and/or } \\
\text { schedule errors } \geq 12 \mathrm{~h}\end{array}$ \\
\hline \multirow{3}{*}{ Non adherent } & 4 & $\begin{array}{l}\text { Poor drug adherence: } \\
\text { Drug holidays for } 2-3 \\
\text { days and/or missing } \\
\text { doses } \geq 1 / \text { week }\end{array}$ \\
\hline & 5 & $\begin{array}{c}\text { Very poor drug } \\
\text { Adherence } \\
\text { Systematically skipping a } \\
\text { daily dose and/or drug } \\
\text { holidays } \geq 6 \text { days }\end{array}$ \\
\hline & 6 & $\begin{array}{l}\text { Discontinuation: Drug } \\
\text { discontinuation }\end{array}$ \\
\hline
\end{tabular}

\section{Ethics approval and consent to participate}

The Ethical Review Committee of Ziauddin University has reviewed this project and gave approval to conduct this study (Reference number 0190212MAPHAR). All participants involved in the study provided written consent.

\section{RESULT}

200 adult participants were enrolled in the study were educated. Majority of the participants were male (69\%). $64 \%$ of the participants had diabetes mellitus as co-morbid and $26 \%$ had hypertension. Around $36 \%$ of the patient were taking less than 3 medications where as $30 \%$ of the patient were taking around 6-7 medications. Based on the selfassessment tool, $76 \%$ of patient were found full adherent, however, $23 \%$ were found partial adherent. The detail about the demographic characteristics of participants is shown in Table 2.

Table 2. Demographic characteristics of participants.

\begin{tabular}{|c|c|c|}
\hline & Frequency & $\%$ \\
\hline \multicolumn{3}{|l|}{ Gender } \\
\hline Male & 139 & 69 \\
\hline Female & 61 & 31 \\
\hline \multicolumn{3}{|l|}{ Education } \\
\hline Yes & 200 & 100 \\
\hline No & 0 & 0 \\
\hline \multicolumn{3}{|l|}{ Employed } \\
\hline Yes & 86 & 43 \\
\hline No & 114 & 57 \\
\hline \multicolumn{3}{|l|}{ Diabetes Mellitus } \\
\hline Yes & 128 & 64 \\
\hline No & 72 & 36 \\
\hline \multicolumn{3}{|l|}{ Hypertension } \\
\hline Yes & 52 & 26 \\
\hline No & 148 & 74 \\
\hline \multicolumn{3}{|l|}{ Types of Antidepressants } \\
\hline SSRI & 152 & 76 \\
\hline Tricyclic Antidepressants & 48 & 24 \\
\hline \multicolumn{3}{|l|}{ Medications for other disease } \\
\hline Yes & 200 & 100 \\
\hline No & 0 & 0 \\
\hline
\end{tabular}

Factors such gender, education, employment status, total number of medications were tested with Kendall correlation analysis to determine their relationship with adherence at baseline, 3 months and 6 months. Gender was found to inversely related to adherence at baseline and 3 months and directly related at 6 months. Education was found inversely related at all interval of adherence. Employment status was found directly related at baseline and at 3 months and 
inversely related at 6 months. Total number of medications prescribed had mixed result. None of the relationships were found statistically significant. The details of correlation analysis of factors with medication adherence is shown in Table 3.

Table 3. Correlation Analysis of Factors with Medication Adherence.

\begin{tabular}{|c|c|c|}
\hline Combination & $\boldsymbol{r k}$ & $\boldsymbol{P}$ \\
\hline $\begin{array}{c}\text { Gender-Baseline Medication } \\
\text { Adhere }\end{array}$ & -0.027 & 0.7 \\
\hline $\begin{array}{c}\text { Gender-Month 3 Medication } \\
\text { Adherence }\end{array}$ & -0.036 & 0.61 \\
\hline $\begin{array}{c}\text { Gender-Month 6 Medication } \\
\text { Adherence }\end{array}$ & 0.006 & 0.32 \\
\hline $\begin{array}{c}\text { Education-Baseline Medication } \\
\text { Adhere }\end{array}$ & -0.029 & 0.67 \\
\hline $\begin{array}{c}\text { Education-Month 3 Medication } \\
\text { Adherence }\end{array}$ & -0.018 & 0.79 \\
\hline $\begin{array}{c}\text { Education-Month 6 Medication } \\
\text { Adherence }\end{array}$ & -0.006 & 0.93 \\
\hline $\begin{array}{c}\text { Employment Status-Baseline } \\
\text { Medication Adherence }\end{array}$ & 0.01 & 0.98 \\
\hline $\begin{array}{c}\text { Employment Status-Month 3 } \\
\text { Medication Adherence }\end{array}$ & 0.05 & 0.47 \\
\hline $\begin{array}{c}\text { Employment-Month 6 Medication } \\
\text { Adherence }\end{array}$ & -0.04 & 0.49 \\
\hline $\begin{array}{c}\text { Total Number of Medications- } \\
\text { Baseline Medication Adherence }\end{array}$ & 0.09 & 0.14 \\
\hline $\begin{array}{c}\text { Total Number of Medications-Month } \\
\text { 3 Medication Adherence }\end{array}$ & -0.03 & 0.63 \\
\hline $\begin{array}{c}\text { Total Number of Medications-Month } \\
6 \text { Medication Adherence }\end{array}$ & 0.003 & 0.96 \\
\hline
\end{tabular}

\section{DISCUSSION}

This is the first study of Pakistan on medication adherence that evaluated its factors over a period of six months. Our studies showed that factors such as gender, education, employment and medication prescribed earlier have a major role in adherence of antidepressants.

Medication adherence is a highly complex phenomenon which involves more than two hundred factors influencing it [18]. It cannot be confined to diseases, drugs or time period. It is a continuous process for acute to chronic diseases for a life time process of medication administration [19]. Factors have been collectively described by WHO into five dimensions namely patient related, socio-economic, healthcare system related, therapy related and clinical related factors [20]. It is imperative to determine factors that effects adherence in each disease based on geographical location due to difference of culture, ethnicity, social values and belief.

Different studies conducted in Pakistan have shown that medication non-adherence is a major concern in the treatment of depression. A study conducted in psychiatric ward revealed that patients suffering from depression had the highest (31.5\%) incidence of nonadherence amongst other psychiatric disorder [21]. A study revealed the major factors associated with nonadherence in psychiatric patients include sedation (30\%), medication cost (22\%), forgot to take medication (36\%); and inability of the physicians to explain timing and dose $(92 \%)$ or benefit of medication (76\%). Other factors that may contribute to non-adherence are: not knowing diagnosis $(50.7 \%)$, incautious to ADR (86.3\%) [22]. Other factors contributing to low adherence to antidepressants include low age, worker or student status, higher daily dose, doctor-patient relationship [23]. A study showed that relationship problems, financial difficulties and low educational level are positively associated with depressive disorders [24]. Appropriate discussion about the adverse effects affected significantly upon antidepressant adherence [25]. Ethnicity seems to have less impact on nonadherence of antidepressants [26]. These studies provided a cross-sectional perspective of factors effective adherence. Our study has shown that the relationship of different factors with adherence changes with time. Like many earlier studies, our study was able to show relationship of gender, education employment and morbidity with adherence of antidepressants. Relationship with number of medication taken was first time examined. Our study shows that patients already taking medications for different diseases have better adherence to antidepressants.

Our study has several limitations due to its single centred nature, specific location and low generalization. Our study was only conducted in Karachi, a major metropolitan city of Pakistan and geographical location have an impact on adherence. Though we didn't include ethnicity as a factor in our study, the location the study conducted is a mixed society including individuals from different part of 
Pakistan. Other factors such as age, ethnicity, and social status were not assessed in our study. Since the participants enrolled below to nearly same age group and socioeconomic status, it makes our study valuable in this sub-group of population.

\section{CONCLUSION}

Factors play a vital role in understanding the barriers in medication non-adherence. Factors effecting medication adherence change with respect to the duration of therapy. Gender, employment, morbidity and number of medication taken earlier have significant influence on medication adherence of antidepressants in depressed patients. It is recommended that more studies should be conducted in involving patients from different diseases, different geographical location and economic status.

\section{REFERENCES}

1. Elliott RA, Shinogle JA, Peele P, Bhosle M, Hughes DA. Understanding medication compliance and persistence from an economics perspective. Value Health $J$ Int Soc Pharmacoeconomics Outcomes Res. 2008 Aug;11(4):600-10.

2. Adams AJ, Stolpe SF. Defining and Measuring Primary Medication Nonadherence: Development of a Quality Measure. J Manag Care Spec Pharm. 2016 May;22(5):516-23.

3. Clifford S, Coyne K. What is the Value of Medication Adherence? Journal of Managed Care \& Specialty Pharmacy. 2014;20(7):650.

4. Sabaté E. Adherence to long-term therapies: evidence for action. 2003 [cited 2019 Aug 31]; Available from: https://apps.who.int/iris/handle/10665/42682

5. WHO | Depression [Internet]. WHO. [cited 2017 Apr 26]. Available from: http://www.who.int/topics/depression/en/

6. Bushra R, Aslam N. Prevalence of Depression in Karachi, Pakistan [Internet]. 2010 [cited 2017 Apr 26]. Available from: http://www.omjournal.org/images/46_m_deatials_p df_.pdf

7. Health WC on $M$ and, Organization $W H$. Macroeconomics and health: investing in health for economic development: executive summary. Macroéconomie et santé: investir dans la santé pour le développement économique: résumé d' orientation du rapport [Internet]. 2001 [cited 2017 Apr 29]; Available from: http://www.who.int/iris/handle/10665/42463

8. James Jefferson MD. Patient Compliance in Depression. Am J Manag Care [Internet]. 2000 Feb 1 [cited 2017 Apr 26];6(Creating an Optimal
Strategy for Improving Outcomes in Depression 2 Suppl). Available from: http://www.ajmc.com/journals/supplement/2000/20 00-02-vol6-n2suppl/feb00-699ps031-s038

9. Fournier JC, DeRubeis RJ, Hollon SD, Dimidjian S, Amsterdam JD, Shelton RC, et al. Antidepressant Drug effects and Depression Severity: A Patient-Level Meta-Analysis. JAMA J Am Med Assoc. 2010 Jan 6;303(1):47-53.

10. JOINT FORMULARY COMMITTEE. British National Formulary. [Internet]. 73rd ed. London: BMJ Group and Pharmaceutical Press; 2017 [cited 2017 Apr 29]. Available from: https://www.bnf.org/products/books/

11. Khan M. COMPARISON OF ESCITALOPRAM A NEW SSRI WITH TCA, CLOMIPRAMINE IN MAJOR DEPRESSIVE DISORDER: A double blind study. Pak J Med Sci. 2004;20(3):238-41.

12. Tamburrino MB, Nagel RW, Chahal MK, Lynch DJ. Antidepressant Medication Adherence: A Study of Primary Care Patients. Prim Care Companion J Clin Psychiatry. 2009;11(5):205-11.

13. Piguet V, Cedraschi C, Dumont P, Desmeules J, Allaz A-F, Dayer P. Patients' representations of antidepressants: a clue to nonadherence? Clin J Pain. 2007 Oct;23(8):669-75.

14. Mark TL, Joish VN, Hay JW, Sheehan DV, Johnston SS, Cao Z. Antidepressant use in geriatric populations: the burden of side effects and interactions and their impact on adherence and costs. Am J Geriatr Psychiatry Off J Am Assoc Geriatr Psychiatry. 2011 Mar;19(3):211-21.

15. Sirey JA, Bruce ML, Kales HC. Improving antidepressant adherence and depression outcomes in primary care: the treatment initiation and participation (TIP) program. Am J Geriatr Psychiatry Off J Am Assoc Geriatr Psychiatry. 2010 Jun;18(6):554-62.

16. Amir M, Feroz Z, Beg AE. A new health care professional-based model for medication adherence. Patient Prefer Adherence. 2018 Oct 10;12:2085-91.

17. Sidorkiewicz S, Tran V-T, Cousyn C, Perrodeau E, Ravaud P. Development and validation of an instrument to assess treatment adherence for each individual drug taken by a patient. BMJ Open. 2016 May 10;6(5):e010510.

18. Fenerty SD, West C, Davis SA, Kaplan SG, Feldman SR. The effect of reminder systems on patients' adherence to treatment. Patient Prefer Adherence. 2012;6:127-35.

19. Vrijens B, De Geest S, Hughes DA, Przemyslaw K, Demonceau J, Ruppar T, et al. A new taxonomy for describing and defining adherence to medications. $\mathrm{Br} J$ Clin Pharmacol. 2012 May;73(5):691-705.

20. Medication Compliance and Persistence:Terminology and Definitions [Internet]. [cited 2017 Nov 5]. Available from: https://www.ispor.org/sigs/medcompliance/Medicat ionComplianceandPersistence.asp 
21. Taj R, Khan S. A STUDY OF REASONS OF NONCOMPLIANCE TO PSYCHIATRIC [Internet]. 2017 [cited 2017 Apr 29]. Available from: http://ayubmed.edu.pk/JAMC/PAST/172/Rizwan\%20Taj.htm.

22. Ganatra HA, Bhurgri H, Channa R, Bawany FA, Zafar SN, Chaudhry RI, et al. Educating and Informing Patients Receiving Psychopharmacological Medications: Are Family Physicians in Pakistan up to the Task? PLOS ONE. 2009 Feb 27;4(2):e4620.

23. Shigemura J, Ogawa $T$, Yoshino A, Sato $Y$, Nomura S. Predictors of antidepressant adherence: results of a Japanese Internet-based survey. Psychiatry Clin Neurosci. 2010 Apr;64(2):179-86.
24. Mirza I, Jenkins R. Risk factors, prevalence, and treatment of anxiety and depressive disorders in Pakistan: systematic review. BMJ. 2004 Apr 1;328(7443):794.

25. Brown C, Battista DR, Sereika SM, Bruehlman RD, Dunbar-Jacob J, Thase ME. How can you improve antidepressant adherence? J Fam Pract. 2007 May;56(5):356-63.

26. Ayalon L, Areán PA, Alvidrez J. Adherence to Antidepressant Medications in Black and Latino Elderly Patients. Am J Geriatr Psychiatry. $2005 \mathrm{Jul}$ 1;13(7):572-80.

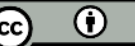

(c) (i)
This is an Open Access article distributed under the terms of the Creative Commons Attribution License (http://creativecommons.org/licenses/by/4.0), which permits unrestricted use, distribution, and reproduction in any medium, provided the original work is properly cited. 